\title{
Comunicación publicitaria en la industria de la moda: branded content, el caso de los fashion films
}

\section{Advertising communication in the fashion industry: branded content, the case of fashion films}

\author{
Francisco Arbaiza Rodriguez y Shirley Huertas García1 \\ Recibido: 09-10-2017 - Aceptado: 08.01.2018 \\ DOI: https://doi.org/10.26441/RC17.1-2018-A1
}

\begin{abstract}
RESUMEN: En estos tiempos en que el consumidor cada vez es más exigente y rechaza la comunicación comercial invasiva, las marcas deben apostar por nuevas formas de comunicación, cuyo contenido sea relevante, llame la atención sin saturar, y que logre una verdadera conexión entre la marca y el consumidor. El presente artículo aborda una de las nuevas tendencias de publicidad, el branded content, una fórmula que da un paso más allá del product placementy procura al consumidor un contenido relevante. En concreto, se analiza el caso de los fashion films, un formato publicitario que ha irrumpido en el sector de la moda y los productos de lujo con mucho éxito, y cuyo fundamento consiste en formular un contenido creado específicamente para determinada marca de moda, con una composición en el que predomina la belleza y la estética, pero que, sobre todo, permite comunicar los valores y personalidad de marca y así conectar con el consumidor.
\end{abstract}

Palabras clave: branded content; fashion films; publicidad; storytelling; moda.

ABSTRACT: In a present where the consumer is increasingly demanding and rejects intrusive comercial communications, brands must venture on new forms of communication, with content that is relevant and attention-grabbing, without saturating, and at the same time achieve a true brand-consume connection. This article addresses one of the new advertising trends, branded content, a formula that goes beyond product placement and proposes relevant content to the consumer. Specifically, is analyzed the case of fashion films, an advertising format that has broken out in the sector of fashion and luxury products with great success, and whose objective is to generate content specifically for a particular fashion brand, in which beauty and aesthetic predominates, but above all, allows to communicate the values and personality of the brand and thus connect with the consumer.

Key words: branded content; fashion films; advertising; storytelling; fashion industry.

Francisco Arbaiza Rodríguez es Doctor en Comunicación Pública por la Universidad de Navarra, Profesor y Jefe del Área de Comunicaciones de Marketing de la Facultad de Comunicación de la Universidad de Piura. Ha investigado recientemente sobre el Marketing Experiencial y su influencia en el comportamiento del consumidor. francisco.arbaiza@udep.pe, http://orcid.org/0000-0003-0539-3184

Shirley Huertas Garcia es Licenciada en Comunicación por la Universidad de Piura. huertas.shirley@gmail.com 


\section{Introducción}

Hasta hace algún tiempo la publicidad ha perseguido como objetivo principal alcanzar a su público meta buscando su atención y su interés a través de mensajes repetitivos centrados en el producto. Las condiciones del escenario actual han hecho que esta situación cambie. Hoy, para las marcas, ya no es suficiente referirse solamente al producto y capturar la atención del consumidor por corto tiempo (Del Pino y Castelló, 2015). Lo que las marcas pretenden es conectar con el consumidor a nivel emocional, aproximarse a su estilo de vida, crear un vínculo y como consecuencia que el mismo consumidor la incluya en su consideration set (Díaz, 2016), que se interese por ella y por lo que pueda aportar a su estilo de vida (Costa-Sánchez, 2014). De esta manera, el consumidor, ha pasado de ser un simple receptor pasivo a ser un actor activo en el proceso de marketing: Un prosumidor, que participa de la comunicación (Costa-Sánchez, 2014). Así, el consumidor se ha revelado como "un individuo más crítico, más escéptico y más exigente con las marcas" (Torres, 2013, p.15).

Esta situación ha ocasionado que la publicidad evolucione y se reinvente y convierta a las mismas marcas en fuente de entretenimiento a través de nuevos formatos. A través del branded content las marcas han empezado a crear sus propios contenidos impregnados de sus valores y del universo de marca que el público está interesado en ver y compartir.

Con este nuevo enfoque, el conteni- do del anuncio está al servicio de la marca y no tiene como único fin la venta del producto, sino la vinculación marca-consumidor. Bajo esta condición es que en la industria de la moda surgen los fashion films.

A través de los fashion films las marcas de moda buscan interactuar con sus consumidores invitándolos a participar de su universo de marca a través de relatos impregnados de valores que conectan con sus emociones. Relatos cuidadosamente realizados que combinan arte, moda, música, cine y publicidad; logrando con ello un engagement con el público, destancando la belleza y estética de la pieza audiovisual (Del Pino y Castelló, 2015).

El mensaje tradicional en el medio convencional adolece cada vez más de eficacia. El público masivo está hastiado de mensajes impuestos por el anunciante, y la audiencia especializada demanda contenidos específicos. Esta realidad es todavía más acusada cuando hablamos de un sector tan cultivado y elitista como el de la moda. Es por esto que la realidad del nuevo escenario que se vive en comunicación no da más opción que acatar las nuevas reglas, flexibles y amoldables a cada sector, pero ineludibles. (Del Pino y Castelló, 2015, p.123)

En este artículo se pretende analizar esta nueva tendencia publicitaria de los fashion films en el sector de la moda. Para ello se realizará un análisis desde la retórica de Quintiliano al fashion film Timeless Elegance realizado en 2017 por la marca Lacoste, The Tale of Thomas Burberry realizado en el año 2016 por la 
marca Burberry y Reincarnation realizado por la marca Chanel en 2015.

Para ello se proponen cinco variables de estudio que son los elementos de la retórica de Quintiliano: Inventio, Elocutio, Dispotitio, Memoria; y Actio y Pronuntiatio. Se analizará la coherencia entre todos los elementos y la marca o valores que la marca desea comunicar. De esta manera se podrá comprobar nuestra hipótesis "Los fashion films en globan los valores y personalidad de la marca; y crean una conexión emocional con el receptor".

Como ya se ha mencionado, la publicidad tradicional no es suficiente, el consumidor ya no cree en las promesas de marca (Godin y Bravo, 2006). Por eso es importante el estudio de nuevos formatos publicitarios como son el branded content y los fashion films pues son nuevas estrategias que buscan la satisfacción y lealtad del cliente con la marca. Como ya es comúnmente sabido, la conexión emocional con el consumidor es fundamental (Gobé, 2010), por lo que las marcas deben crear nuevas propuestas de valor que complementen su experiencia de consumo, y sobre todo, que le brinden entretenimiento a través de contenido creativo e interesante por sí mismo (Arbaiza, 2017).

\section{Marco teórico}

\subsection{Branded content, un nuevo enfoque más allá del product placement}

Como se mencionó anteriormente, en la actualidad estamos ante un nuevo escenario de marketing en el cual el engagement o identificación que logre sen- tir el consumidor es lo que lo impulsa a tomar una decisión o acción. El consumidor ha pasado de ser un mero espectador a ser un agente activo, que espera de la marca una experiencia de valor. Ha pasado a ser un "prosumidor" (Ahluwalia y Miller, 2014), una persona que vive su condición de consumidor de manera activa, asumiendo un nuevo papel (Costa-Sánchez, 2014 y Martin, 2015).

El prosumidor se aleja de la publicidad de interrupción -la publicidad tradicional- y se aproxima a experiencias memorables, participa, comparte y produce contenido; se encarga de promocionar a través de su red de contactos experiencias de marca interesantes, sobre todo aquellas que hayan conectado con él, y aquellos mensajes con los que se haya sentido identificado (De Assis, 2014; Gambetti y Graffigna, 2011).

Este nuevo escenario ha obligado a las marcas a generar un engagement que vaya más allá de la transacción comercial y buscar nuevos formatos y herramientas que porten contenido e interés para el público (Del Pino y Castelló, 2015; Martin, 2015).

Es así como surge el branded content, una propuesta que, a diferencia del product placement, en la que el producto solo se inserta en el contenido, consigue que el producto sea el contenido en sí mismo y con ello "las marcas crean su propio contenido para compartirlo con los usuarios, pretendiendo ya no tanto anunciarse sino relacionarse y compartir experiencias" (Del Pino, et al. 2013, p. 20). Dentro del branded content, la marca es un elemento activo que tiene 
el control sobre el mensaje, mientras que en el product placement se presenta de una forma más pasiva, debido a que existe un guion previamente definido. Horrigan (2009) define el branded content como:

Una fusión de publicidad y entretenimiento en un mismo producto de comunicación al servicio del marketing que se integra en la estrategia global de marca de una organización y que está destinada a ser distribuida como contenido de entretenimiento con un elevado nivel de calidad. (p.51)

El branded content dista mucho de la publicidad tradicional principalmente en la forma de presentar a la marca. En la publicidad tradicional el contenido se percibía intrusivo desde el punto de vista del consumidor; la persuasión era muy evidente, primaba el producto y sus características. El branded content presenta más elementos narrativos que persuasivos, las estrategias persuasivas que solían ser evidentes en la publicidad tradicional ya no son tan visibles (De Assis; Tur-Viñes y Segarra; Del Pino y Castelló, 2014).

En este nuevo formato ya no se trata de elaborar campañas puntuales sino que las marcas propongan ideas y contenidos que puedan mantenerse en el tiempo y conecten con el consumidor generando lealtad de marca (Tur-Viñes y Segarra, 2014). "El branded content permite al anunciante generar y ofrecer contenidos memorables y relevantes en los que se presenta a la marca de manera menos agresiva y más sutil y duradera que en la publicidad tradicio- nal” (Del Pino y Castelló, 2015, p.8). Este formato más que persuadir pretende generar interés, aporta contenido que los usuarios quieren conocer (Costa-Sánchez, 2014).

Entre las características más resaltantes del branded content tenemos (Del Pino y Castelló, 2015):

1. Uso de Big data: Se refiere al análisis de datos procedentes de medios sociales que la empresa tiene a su disposición sobre los hábitos y actividades de los usuarios: gustos, preferencias, intereses, estilo de vida.

2. Storytelling: Las marcas deben ser capaces de transmitir sus valores a través de historias coherentes con la marca, que conecten con el consumidor y complementen la experiencia de consumo del usuario.

3. Viralidad: El branded content busca aprovechar las redes sociales para amplificar la difusión de su mensaje. $\mathrm{Al}$ ofrecer contenidos de valor e interés, estos se vuelven virales porque el usuario los comparte con los suyos.

4. Transmedialidad: La mayoría de estrategias que incluyen al branded content están pensadas bajo el formato de la transmedialidad porque permite a los usuarios participar sobre los contenidos elaborados.

Además, Lorán (2017) señala que el branded content permite adaptarse a diferentes soportes:

1. Soporte audiovisual: series de televisión, reality shows, programas cortos, patrocinados, $\mathrm{TV}$ en directo y canales on-line de televisión. 
2. Soporte digital: plataformas sociales, experiencias interactivas, dispositivos móviles y webs de experiencia.

3. Eventos: deportivo y cine.

4. Juegos: advergames, aplicaciones móviles, entre otras.

5. Música: artistas esponsorizados, conciertos en directo o videoclips musicales.

6. Impresos: revistas y libros.

A través del branded content, las marcas producen contenidos propios que entretienen y comunican la identidad y valores de la marca, con ello, la comunicación se lleva a un nivel más profundo y relevante para el target (De Assis, TurViñes y Segarra, 2014). Este efecto se ha amplificado con la llegada de las redes sociales, que se han convertido en un nuevo espacio en el cual pueden adquirir mayor visibilidad, fácil acceso y la posibilidad de que los consumidores compartan dichos contenidos (Lorán, 2017).

Asimismo, las redes sociales han logrado unir comunidades sin importar la distancia geográfica, impulsando la creación rápida de prototipos culturales, surgiendo nuevos talentos y nuevos géneros de contenido (Holt, et al., 2016).

\subsection{Fashion Films: Moda y Comunicación}

El hecho de que publicidad tradicional se haya vuelto cada vez más ineficaz y que el público esté hastiado del sinfín de mensajes impuestos por los anunciantes es igual o más grave en el ámbito de la moda, un sector cultivado y elitista que suele demandar contenidos específicos (Del Pino y Castelló, 2015).

En este mercado las marcas precisan un formato de publicidad que traslade su universo y valores de marca al consumidor. Así es como surge el fashion film, un recurso que permite contar una historia creada específicamente para la marca (Del Pino y Castelló, 2015).

En efecto, de un tiempo a esta parte, las marcas de moda ya han constatado que sus tiendas no son tan visitadas como antes, y que se han vuelto simples lugares de exhibición más que centros de compra; asimismo, las revistas de moda, que hasta hace poco eran el referente para encontrar tendencias, hoy debido a la inmediatez de internet y el aumento de poder del consumidor, han quedado como referencias de segundo orden (Díaz, 2016). Por ello, las firmas de moda empezaron a interactuar con sus clientes y vincular contenidos en las redes sociales, animando a los usuarios a participar y opinar (Del Pino y Castelló, 2015; Díaz, 2016; Martin, 2015).

Del Pino y Castelló (2015) define a los fashion films como:

Producciones audiovisuales, a modo de cortometrajes, al servicio de una marca, caracterizadas por un estilo comunicativo en el que predomina la belleza y la estética extremadamente cuidada del mensaje -heredada de la fotografía de moda-, sobre el producto y/o la marca en sí mismos. (p.14)

Este formato fusiona arte, cine, música, moda y publicidad; y presenta las siguientes características (Mijovic, 2013; Martín, 2014; Caerols y De la Horra, 2015; Del Pino y Castelló, 2015): 
1. Producción y estética visual muy cuidada: Estética heredada de la fotografía de moda y en ciertos casos, con un estilo fantástico y onírico. El fashion film busca el deleite estético, a través del uso de la belleza, el equilibrio, la armonía.

2. Duración superior a los spots tradicionales (1-5 min.)

3. Ritmo narrativo rápido, fresco y espontáneo.

4. Busca la viralidad, llamar la atención. Se pueden transmitir por televisión o cine, sin embargo están creados para una difusión digital.

5. Es más sensorial que persuasivo, apela a las emociones.

6. El storytelling y la serialización son las estrategias más utilizadas por los fashion films para crear una conexión con la marca. La serialización permite generar una adhesión con el consumidor, y además permite realizar una narración más detallada.

Es importante mencionar que la imagen en movimiento, como una forma de mostrar la moda, ya ha sido utilizado desde la época del cine mudo y a través de documentales de moda y reportajes (Uhlirova, 2013). Desde 1910 en que Warner anunció su corsé a través de un formato boceto comedia corta convencional que concluía con una secuencia de animación stop-motion, hasta la década de los ochenta en que la televisión estuvo más abierta a la elaboración de programas dedicados a la moda, el proceso de búsqueda de fórmulas para conectar con el consumidor a través de films ha tenido una evolución sostenida (Mijovic, 2013). Hoy las grandes marcas de moda han comenzado a invertir más presupuesto en fashion films, y su difusión a través de internet, junto con, o en lugar de los canales más tradicionales: televisión, cine, revistas (Uhlirova, 2013).

Lo que se busca es que los consumidores interpreten las historia que la marca les narra a través del fashion film y las convierta en una experiencia memorable, que sean absorbidos por ella e incluso lleguen a integrar sus propias experiencias en dicha historia (JaeEun, et al., 2016; Granitz y Forman, 2015).

\subsubsection{El papel determinante del storytelling en los fashion films}

Como se ha mencionado previamente, una de las características del branded content es el storytelling; conceptos que siempre se mantendrán enlazados debido a que se proveen mutuamente de historias que narrar y medios a través de los cuales poder contarlas. Las narraciones llevan a razonamientos que conllevan a conclusiones -de la misma forma que la emoción lleva a la acción-, por ello esas historias deben lograr despertar una emoción relacionada con el mensaje y la idea que se quiere transmitir en el consumidor (Del Pino, et al. 2013).

Mijovic (2013) afirma que hay tres tipos diferentes de fashion films: (1) los "no narrativos", que son como un tipo de editorial de revistas con movimiento; (2) los "narrativos convencionales", que enfocan la moda como un símbolo de aspiración y (3) los "narrativos orgánicos" en donde el protagonismo se lo 
llevan las prendas de ropa, estas son el centro de la trama. La autora además precisa que incluso los fashion films no narrativos y orgánicos pueden incluir la narración o storytelling y serialización.

El storytelling dentro del fashion film representa un elemento importante que no se basa en contar historias, sino en hacerlo de una manera en la que ese mensaje cobre fuerza. Las firmas cuentan estas historias de manera creativa, procuran seducir e introducir al espectador en un mundo imaginario, donde la marca es la protagonista aparentando no serlo, actuando como un mero narrador (Sáez y Alvarado, 2015; Díaz y García, 2016).

Michaud (como se citó en Díaz y García, 2016) afirma que los productos de lujo no comunican rasgos funcionales, pragmáticos; ellos transmiten símbolos que se refieren al conjunto de valores como la excelencia, la calidad, la belleza o el poder. Ya que las marcas de lujo no pueden recurrir a la argumentación racional deben evocar un atractivo irracional mediante la seducción. El objetivo es atraer, provocar el compromiso y crear el deseo y esto se logra a través de valores emocionales.

De esta manera, los fashion films, muestran personajes universalmente reconocibles como el héroe, el villano, el aventurero o el inocente; y valores como el honor, la venganza, la libertad, la rebelión, el amor o la inocencia. Incluso en muchos casos, los valores presentados se convierten en otro personaje de la trama (Díaz y García, 2016).

Con el storytelling se consigue que el espectador, que ve la película volunta- riamente, no la considere intrusiva. Esta característica resulta determinante en un entorno como internet, -principal canal de difusión de los fashion films-, ya que el espectador suele prestar atención de manera breve y busca contenidos activamente (Sáez y Alvarado, 2015; Díaz y García, 2016).

\section{Metodología}

En este artículo se pretende estudiar el fenómeno de los fashion films partiendo de la hipótesis: Los fashion films engloban los valores y personalidad de la marca; y crean una conexión emocional con el receptor. Para comprobarla se ha optado por una metodología de análisis desde la retórica de Quintiliano aplicada en la comunicación comercial.

La retórica es una ciencia clásica del discurso, así como la poética. El lenguaje es la base de la retórica como ciencia y como técnica de comunicación persuasiva porque "se configura y se va completando desde una atenta y constante indagación en las posibilidades relacionadas con la influencia en los receptores" (Albaladejo, 2005, p.9).

Por otro lado, la publicidad persigue un fin específico que es la persuasión, fin que también persigue la retórica desde su creación hace más de 2500 años. El hecho de que ambas compartan el mismo fin, permite que la retórica sea aplicable como una estrategia o método para la publicidad para transmitir o potenciar la capacidad persuasiva del mensaje.

La retórica posee una maleabilidad que le ha permitido adaptarse a distintos 
códigos y medios de expresión y comunicación. Esto ha permitido que la alianza entre la retórica y la comunicación comercial funcione eficazmente. "La retórica le ha cedido todos los ya antiquísimos procedimientos a la publicidad para que ella los explote a su manera; y ésta en loor de la verdad lo ha conseguido con asombrosa eficiencia" (Spang, 2005, p.28).

En este sentido, la retórica de Quintiliano funciona como una base sólida para la elaboración del anuncio publicitario; así como de los fashion films porque no solo suministra recursos sino una filosófica del discurso y por lo tanto, también del discurso publicitario (Spang, 2005). Esto junto con las técnicas que brinda la tecnología convierte a la retórica en un instrumento excelente para llevar a cabo la persuasión dentro del mensaje publicitario.

La retórica de Quintiliano cuenta con 5 fases o elementos que serán las variables a analizar en los fashion films elegidos: Inventio, Dispotitio, Elocutio, Memoria y Acto y Pronuntiatio.

Inventio: Búsqueda de ideas, argumentos y materiales para tratar un tema preexistente.

Existen 3 puntos importantes de análisis dentro del Inventio: (1) Tema. Un producto o servicio no puede ser un tema. Por tanto, se debe inventar un tema alrededor del cual girará su anuncio. Usualmente se cuenta una mini historia que tiene relación con el servicio o producto que se quiere publicitar, aunque sea de manera alusiva. Asimismo, la búsqueda del tema debe tomar en cuenta a los consumidores, al público objetivo y el medio a través del cual se proyecta difundir el anuncio (Spang, 2005). (2) Gancho. Dentro de los anuncios existe un gancho, que es el elemento verbal y/o icónico destinado a atraer la atención y despertar el interés del público, este elemento tiene mucha importancia porque en la mayoría de los casos será decisivo para lograr que el espectador continúe viendo el anuncio o lo deje de lado. (3) Orientación. En cuanto a la orientación, existen dos opciones: información y emocionalización (Spang, 2005).

Dispotitio: Disposición del anuncio publicitario.

Existen innumerables variantes en cuanto a la disposición de un anuncio publicitario; sin embargo, con frecuencia se obedece a una tripartición en una especie de introducción generalmente complementada con el gancho, luego sigue la parte central que contiene la presentación del producto o la sugerencia de los efectos materiales o psicológicos que produce. Finalmente, el anuncio se cierra con el eslogan (Spang, 2005).

Elocutio: Formulación del texto publicitario.

La eficacia del anuncio depende en gran parte de la adecuada selección y formulación del texto, es importante mencionar que la brevedad es un requisito de suma importancia en la publicidad -menos, es más-; sobre todo en el gancho y eslogan del anuncio (Spang, 2005).

\section{Memoria:}

Es importante que el receptor recuerde lo anunciado en la publicidad, 
porque si no es así, el anuncio sería un fracaso. Si el receptor no recuerda lo anunciado, será muy difícil que adquiera el producto o servicio (Spang, 2005).

\section{Actio y Pronuntiatio:}

En la retórica clásica el actio y pronuntiatio se referían a la preparación de la presentación oral del discurso. El orador ensayaba antes de su presentación al público para asegurar la correcta articulación y adecuación del lenguaje corporal, esto incluye la mímica, gesticulación, vestimenta y ambientación.

En el caso del anuncio televisivo, sucede algo similar. "Casi siempre se organiza como una pequeña historia dramática cotidiana en la que unos actores presentan unas circunstancias propicias para promocionar el producto o servicio" (Spang, 2005, p.41). En un anuncio televisivo, los protagonistas y personajes secundarios tienen que actuar como si fuera un teatro con todo lo que implica: decorado, accesorios, vestimenta, maquillaje, movimientos, mímica, gestos, etc. En esta puesta en escena, la música y los efectos juegan un papel importante para completar todo un cuadro que muchas veces tiende a la presentación realista de un segmento de la vida.

En esta última fase del anuncio, en especial para el caso de los fashion films, se requiere un alto nivel de profesionalidad equiparable al de directores y ac- tores cinematográficos ya que la capacidad persuasiva del anuncio está unida a un buen guion publicitario y una buena realización fílmica.

En el caso del actio y pronuntiatio se tomarán en cuenta 4 elementos a analizar: los profesionales a cargo de la realización del anuncio, la historia, la vestimenta y ambientación; y la música. Todos estos elementos deben tener coherencia con la marca que se publicita en el fashion film.

Este análisis será aplicado a 3 fashion films: Timeless Elegance de la marca Lacoste, The tail of Thomas Burberry de la marca Burberry y Reincarnation de la marca Chanel.

Los fashion films elegidos contienen todas las características que necesita un fashion film para considerarse como tal, pertenecen a marcas reconocidas a nivel mundial en el ámbito de la moda que gozan de gran reputación e historia que les ha permitido posicionarse como casas de moda de lujo en la actualidad. Son ejemplos precisos para demostrar la vinculación de los valores de marca dentro de la pieza publicitaria, así como la conexión emocional que logran generar con el consumidor.

\section{Análisis}

Realizaremos el análisis de cada uno de los elementos de la retórica de Quintiliano aplicados a los fashion films elegidos: 


\subsection{Timeless Elegance by Lacoste}

Tabla 1. Ficha de identificación del fashion film de Lacoste

\begin{tabular}{|l|}
\hline Año: Mayo 2017 \\
\hline Duración: 1 min, 30 seg. \\
\hline Plataforma de difusión: Youtube \\
\hline Link: https://www.youtube.com/watch?v=IZC02EQqcXc \\
\hline Director: Seb Edwards \\
\hline $\begin{array}{l}\text { Sinopsis: Dos jóvenes coinciden en una estación de tren y sienten atracción } \\
\text { instantánea pero deciden ignorarla y seguir su camino, decisión de la cual minutos } \\
\text { después se arrepentirán y emprenderán un viaje para coincidir de nuevo. }\end{array}$ \\
\hline Personajes: Mujer (Dorcas Coppin), Hombre (Damien Chapelle) \\
\hline Escenarios: Estación de tren, interiores del tren \\
\hline
\end{tabular}

Fuente: Elaboración propia

\subsubsection{Inventio}

El tema utilizado dentro del fashion film es el amor, que se mostrará a través de una mini historia entre dos personas que coinciden en una estación de tren y sienten atracción instantánea pero deciden ignorarla y seguir su camino, decisión de la cual minutos después se arrepentirán y emprenderán un viaje para coincidir de nuevo. En este caso, el tema del amor genera gran empatía con el público objetivo de la marca Lacoste; adultos jóvenes que pueden verse identificados en la historia ya que no se presenta como un amor adolescente, sino un amor más adulto; incluso los personajes aparentan una edad mayor a los 19 años.

Por su parte, el medio elegido para la difusión del anuncio fue Youtube, lo que implica que el anuncio es audiovisual y tiene elementos sonoros, verbales, visuales. De igual manera el soporte elegido calza perfectamente con el pú- blico objetivo de la marca y al ser una red social tan popular genera gran alcance.

En cuanto al gancho, en el caso de este fashion film es el momento en el que el protagonista masculino decide regresar a buscar a la protagonista que se topó minutos atrás; genera curiosidad en el consumidor por saber qué pasará con ambos personajes, si logra alcanzarla o si la pierde de vista para siempre.

Por último, el autor explica que el anuncio publicitario debe tener una orientación, existen dos casos extremos: información y emocionalización. En este fashion film claramente se pretende emocionar, se apela a los afectos, sensaciones; la historia de amor del film busca hacer sentir algo al consumidor, le hace sentir la emoción, la desesperación de los personajes principales por encontrarse, genera una empatía con ellos. 
Sin embargo, existe un componente de información que se presenta de una manera muy sutil y que pretende mostrar la utilidad del producto. La historia se presta para mostrar el producto icono de la marca, en este caso la camiseta Savoir Faire, como una prenda de calidad, adaptable a todo momento de la vida, incluso para ocasiones agitadas (acompaña al protagonista corriendo, saltando, agachándose, haciendo distintos movimientos para alcanzar a la chica); una prenda intemporal y útil que jamás pierde el estilo.

\subsubsection{Dispotitio}

En el caso del fashion film Timeless Elegance, existe una disposición de tres partes: Una introducción breve, una parte central unida al gancho que ocupa la mayor parte del film, y un cierre con eslogan.

- Introducción: Los dos protagonistas coinciden en una estación de tren, sienten atracción inmediata, amor a primera vista pero cada uno sigue su camino. Se trata de una introducción muy breve que da pie al gancho de la historia.

- Parte central unida al gancho: El protagonista masculino decide volver por la protagonista femenina, intenta alcanzarla subiendo al tren que ella abordó pero su búsqueda se vuelve turbulenta y larga.

- Cierre unido al eslogan: Finalmente los personajes logran coincidir de nuevo luego de un largo tiempo, justo en el momento en que se unen se presenta el eslogan de la marca "Life is a beautiful sport since 1933".

\subsubsection{Elocutio}

En cuanto a la formulación del texto publicitario, en Timeless Elegance se prescinde de diálogos durante el film, pero estos realmente no son necesarios para comprender la historia, ni para darle fuerza a la misma, las imágenes y sobre todo la música son suficientemente potentes para mantener al espectador atento durante el film.

Al final del film se presenta un eslogan que representa completamente a la marca "Life is a beautiful sport since 1933" porque: (1) El producto que se publicita en el film es la camiseta Savoir Faire, primer producto y hoy en día icono de la marca creado en 1933 por René Lacoste, fundador de la marca. (2) La camiseta Savoir Faire fue creada para jugadores de tenis, se reinventó de la camiseta manga larga para otorgar comodidad a los deportistas. Camiseta que pasó rápidamente del guardarropa de tenistas al guardarropa de la gente común y que se utilizaba en cualquier momento debido a su diseno elegante pero relajado. De ahí que viene la frase "La vida es un deporte hermoso desde 1933".

El eslogan engloba toda la historia de la marca, sus inicios y las características de sus productos.

Figura 1. Eslogan de Lacoste

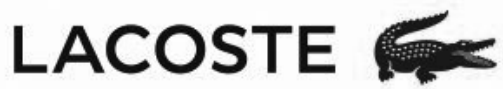 \\ LIFE IS A BEAUTIFUL SPORT SINCE 1933}

Fuente: Lacoste 


\subsubsection{Memoria}

En el film de Lacoste se muestra explícitamente la marca en algunas escenas en las que se hacen planos que permiten ver el logo en la camiseta que utilizan los protagonistas de la historia. La muestra del logo y por consiguiente de la marca es muy sutil durante el fashion film pero se refuerza al final con el eslogan y el nombre de la marca que se presenta en medio de la pantalla en letras grandes.

\subsubsection{Actio y Pronuntiatio}

Un requisito importante que puede hacer una gran diferencia entre un anuncio u otro, especialmente en el caso de los fashion films es que el anuncio esté en manos de profesionales equiparables a directores y actores cinematográficos ya que el anuncio será exitoso en la medida en que su guión y realización fílmica sea óptima.

Es muy común que los fashion films sean dirigidos por directores de cine o fotógrafos de moda; en el caso del fashion film Timeless Elegance; la dirección estuvo a cargo de Seb Edwards, director británico que estudió Bellas Artes en la Universidad de Leeds y es graduado de la Escuela de Cine de la Universidad de Nueva York. Ha trabajado para marcas como Sony, HSBC, Vodafone, AT \& T y COI con el que ganó un León de Oro de Cannes en 2009.

Las actuaciones estuvieron a cargo de Dorcas Coppin, actriz francesa que ha trabajado en films como For Tomorrow, Frank \& Lola y La crème de la crème y Damien Chapelle actor y director belga que ha trabajado en films como Métamorphoses y Peur de rien.

En el caso de los anuncios televisivos se suele mostrar una historia dramática cotidiana. En este caso, la historia se centra en dos chicos que se enamoran a primera vista en la estación de un tren. La historia en este caso sirve como excusa para mostrar el producto dentro de ella, sin embargo, tanto la historia como los personajes y la estética del film son coherentes con la marca Lacoste.

Para entender cómo se refleja la marca en el film, iniciaremos con la historia; se trata de una historia de amor un tema que vive en todas épocas y etapas de la vida, no pasa de moda; es un tema humano por excelencia, es un tema clásico que siempre se repite. La historia de amor tiene una similitud con la marca y sobre todo con el producto que se publicita en el film, la camiseta Savoir Faire: Ambos siguen vigentes, no pasan de moda; puede reinventarse pero no desaparecen. La camiseta Savoir Faire fue creada en 1933 y desde ese entonces sigue confeccionándose y vistiéndose, con el paso de los años su estilo ha evolucionado pero su elegancia relajada se mantiene inalterable.

La música complementa muy bien la historia, se sincroniza con las acciones de los personajes, ayudando a generar curiosidad y a hacer sentir al consumidor la angustia del personaje principal, su desesperación. De esta manera los golpes y ritmo de la música utilizada permiten potenciar la historia.

$\mathrm{Al}$ inicio se mantiene bastante sutil, incluso cuando el gancho se muestra 
(cuando el chico decide regresar por la chica); va subiendo el volumen paulatinamente hasta el momento en que el protagonista masculino vuelve a ver a la protagonista, a partir de allí la música toma potencia e incluso el ritmo cambia, lo que permite como expliqué anteriormente aumentar la sensación de desesperación y de angustia que el personaje siente al perseguir a la chica y no alcanzarla. Posteriormente la música vuelve a bajar de volumen y de ritmo cuando el chico ve alejarse a la chica en otro tren, para volver a tomar potencia, incluso más que al inicio, cuando el chico salta hacia el tren de la chica y ambos empiezan a correr para encontrarse. Finalmente, cuando logran estar juntos la música se desvanece y se escucha el ruido del tren que finaliza el film.
La vestimenta y ambientación está acorde a cada uno de las épocas que presenta el film, la camiseta que utiliza el protagonista en cada época es la misma camiseta que en esos años Lacoste sacó a la venta, de esta manera se muestra como la camiseta se va reinventando con el paso de los años.

El producto, en este caso es la camiseta Savoir Faire; aparece durante todo el fashion film pero en un segundo plano, los personajes lo llevan puesto en casi todas las escenas; sin embargo la atención siempre está centrada en las acciones de los protagonistas.

El producto dentro de este fashion film funciona como complemento de la historia, realmente no desempeña un rol importante para el desarrollo de la misma.

Figura 2. Imágenes de la colección Lacoste
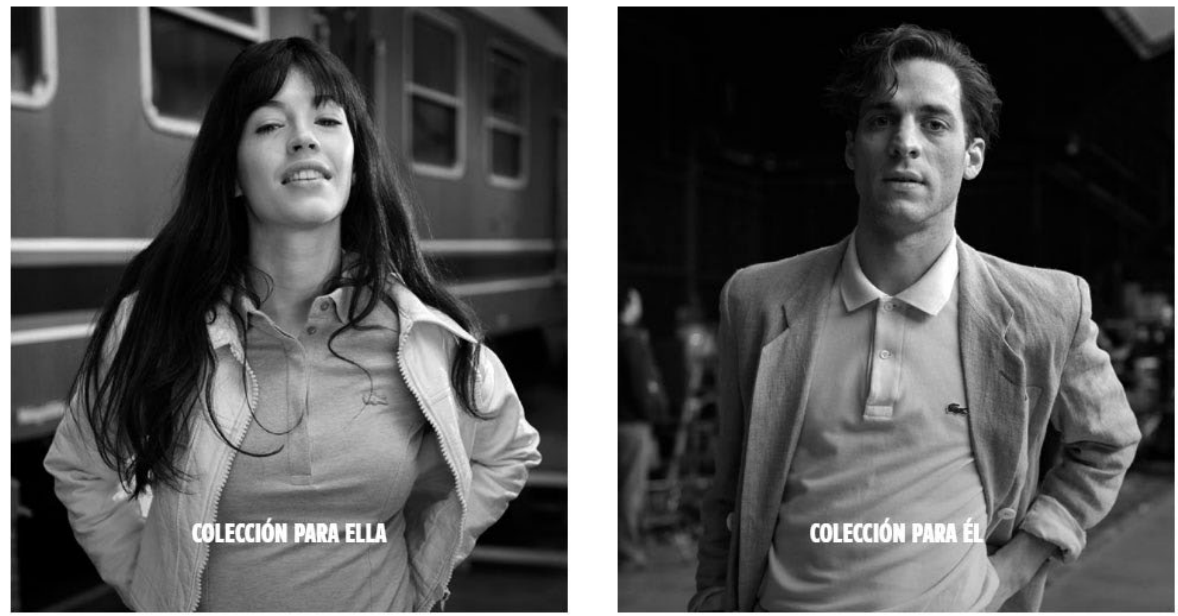

Fuente: Lacoste ${ }^{2}$

2 Disponible en https://global.lacoste.com/es/a-french-story.html. Consultado el 18 de junio de 2017. 


\subsection{The tale of Thomas Burberry - by Burberry}

Tabla 2. Ficha de identificación del Fashion film de Burberry

\begin{tabular}{|l|}
\hline Año: Noviembre 2016 \\
\hline Duración: 3 min, $36 \mathrm{seg}$. \\
\hline Plataforma de difusión: Youtube \\
\hline Link: https://www.youtube.com/watch?v=6D5IZtDCS5c \\
\hline Director: Asif Kapadia \\
\hline $\begin{array}{l}\text { Sinópsis: En este film se relatan los sucesos más importantes del creador de la casa } \\
\text { de moda de lujo Burberry, sucesos que permitieron el éxito de esta firma de moda. }\end{array}$ \\
\hline $\begin{array}{l}\text { Personajes: Thomas Burberry (Domhnall Gleeson), esposa (Sienna Miller), aviadora } \\
\text { (Lily James), esquimal (Dominic Wets). }\end{array}$ \\
\hline
\end{tabular}

Fuente: Elaboración propia

\subsubsection{Inventio}

En este caso, no se ha creado una historia para el fashion film sino que se ha tomado la historia del fundador de la marca Burberry, se ha trabajado una representación biográfica, de esta manera se da a conocer al público la marca de un modo más profundo, contando sus inicios y desarrollo de las piezas icónicas que permitieron que la marca se vuelva en una de las más importantes casas de moda de la actualidad.

Este fashion film en particular posee una diferencia, es contado a modo de tráiler para una película que jamás se filmó ni se filmará. El objetivo de la marca era unir todos los momentos épicos de la vida de Thomas Burberry tanto en el aspecto personal pero principalmente en el profesional en un corto de 3 minutos que creará la idea de un futuro proyecto fílmico que realmente jamás se daría. De esta manera se eligió la plataforma Youtube para difundir el fashion film.
Este film logra captar la atención del consumidor desde el inicio y conforme avanza la historia también aumenta la atención y curiosidad en el espectador. En este sentido no existe un gancho específico y marcado dentro del fashion film.

Por último, la orientación del anuncio es emocional. Se muestran muchos sucesos importantes en la vida de Thomas Burberry, pasando desde los momentos de triunfo, de desesperación y fracaso, hasta los momentos de amor y familia, y de desamor y distanciamiento; todo se une para que el espectador sienta junto al protagonista cada sensación o sentimiento en cada parte de su vida.

Sin embargo, también existe un componente informativo dentro del fashion film. Se da a conocer cómo se creó cada pieza y el nivel de calidad que tienen, un nivel de calidad tan alto que fueron utilizadas por militares y exploradores polares para protegerse del frío en la Antártida. 


\subsubsection{Dispotitio}

En este fashion film existe una introducción muy breve, una parte central que ocupa la mayor parte del film y un cierre.

- Introducción: Se presenta a Thomas Burberry en un taller de confección trabajando en la tela que le daría el primer paso de éxito en su carrera: La Gabardina ${ }^{3}$.

- Parte central: Se muestran partes de la vida del protagonista, empezando por el momento en que conoció a su primer amor y madre de sus hijos; para luego comenzar a mostrar aspectos de su vida profesional: Cuando fue contratado para vestir a exploradores de la Antártida, o cuando una de sus prendas icónicas: el Trenchcoat fue usado por militares en el siglo 20, etc.

- Cierre: Al tratarse de un fashion film realizado a modo de tráiler, no existe un cierre que despeje las dudas o curiosidades del espectador. En un film tradicional el cierre realmente concluye la historia, le otorga un final concreto; en este caso se da paso a una sucesión de imágenes que generan aún más curiosidad al espectador para terminar con un fondo negro y el nombre de la marca.

\subsubsection{Elocutio}

En el film de Burberry se utiliza muy pocos diálogos, casi todo el film se en- tiende solo con las imágenes que presenta.

\subsubsection{Memoria}

En el film de Burberry se muestra el nombre de la marca muy pocas veces, tan solo al inicio y final del fashion film, y de manera sutil en el avión que aparece dentro de la historia. Sin embargo, se deja claro que el protagonista de las historia es el mismísimo Thomas Burberry, creador de la firma de moda; lo que permite que el espectador tenga en mente este dato importante durante todo el film, además se refuerza el recuerdo de la marca al mostrar constantemente las piezas más conocidas y emblemáticas de esta casa de modas.

\subsubsection{Actio y Pronuntiatio}

El fashion film fue dirigido por Asif Kapadia, un director de cine británico ganador del Oscar al mejor largometraje documental por "Amy" en 2015. Además este film fue escrito por Matt Charman, escritor y productor británico nominado por la academia a mejor screenplay por "El puente de los espías" en 2015.

Las actuaciones estuvieron a cargo Domhnall Gleeson, actor irlandés que ha trabajado en películas como Star Wars: Episode VII - The Force Awakens y Star Wars: Episode VIII - The Last Jedi, Harry Potter y las Reliquias de la Muerte - Parte 1 y Parte 2; Sienna

3 En 1879 Thomas Burberry revolucionó la ropa de lluvia que hasta entonces había sido típicamente pesada e incómoda de llevar con la creación de un tejido de algodón innovador, respirable y resistente a la intemperie, la Gabardina. Antes de esta novedad, los tejidos se enceraban o se cubrían de una capa de goma para repeler el agua, haciéndolos más pesados e incómodos para llevar durante mucho tiempo (Burberry, 2017) 
Miller actriz estadounidense que ha trabajado en películas como Factory Girl (2006), Interview (2007) y The Girl (2012); además de Dominic Wets y Lily James en los papeles secundarios.

El fashion film fue filmado para celebrar el 160 aniversario de la marca Burberry, y gira en torno a la vida del creador de la misma, Thomas Burberry. En este film se repasan sucesos importantes en la vida del creador que moldearon su carrera y permitieron que la marca Burberry se posicione como una casa de moda de lujo.

La marca se refleja en el fashion film por varios motivos:

- El hecho de que el film gire en torno a la vida del creador de la marca Burberry ya es una prueba de que la marca se encontrará reflejada en él. Los sucesos que se muestran, claramente no han sido elegidos al azar, han sido cuidadosamente seleccionados para dar a conocer al público como se crearon piezas icónicas de la marca; así como el papel importante que tuvieron estas prendas en la historia y en la vida de otras personas como el caso del Trenchcoat que fue utilizado por militares en la guerra.
- Se inicia el film con la creación de la tela especial para lluvias, la Gabardina $^{4}$, que luego se utilizaría para la confección de prendas que posteriormente serían utilizadas por esquimales para protegerse del frio en sus misiones en la Antártida.

- Se prosigue con el momento en que Betty Dawson, personaje inspirado en la aviadora Betty Kirby Green en los años 20's; década pionera en aviación; logra romper un récord al volar desde Londres a Ciudad del Cabo en un tiempo récord de 25 horas en 1937. Thomas Burberry confeccionó un traje para la piloto e incluso auspició este vuelo especial que tuvo lugar en un avión llamado 'The Burberry'.

- A continuación, se muestra la creación del Trenchcoat especialmente confeccionado para satisfacer las necesidades de los militares a principios del siglo XX. Los epaulettes mostraban el rango de un oficial, mientras que los anillos en D metálicos del cinturón se utilizaron para cargar equipos y armas.

4 La Gabardina resultaba excelente para hacerle frente a condiciones inhóspitas; incluso se utilizaba en tiendas de campaña por sus cualidades ligeras y resistentes al viento.

Disponible en https://es.burberry.com/nuestra-historia/ Consultado el 16 de junio de 2017. 
Figuras 3, 4 y 5. Orígenes de Burberry

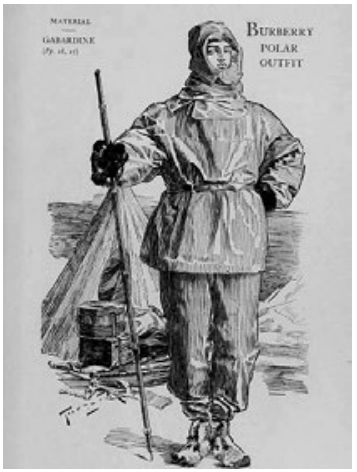

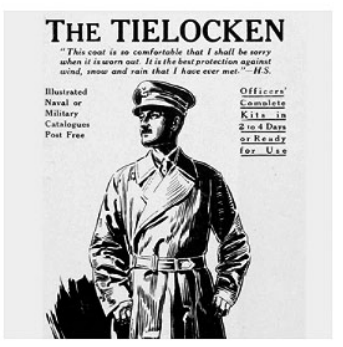

Origins of the trench

The trench coat began as the Tielocken. Patented by Burberry in 1912, it was an unbuttoned style made from gabardine and fastened with a belt.

\section{Fuente: Burberry}

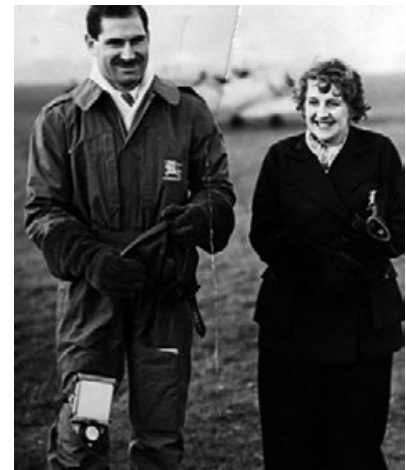

Todos estos momentos importantes para el desarrollo de la marca se combinan con sucesos importantes en la vida personal de Thomas Burberry, se muestran pequeñas escenas de cómo conoció a su esposa, navidad con sus hijos, etc.

Todo el film es un homenaje al creador de la marca, que permite al consumidor conocerlo a fondo, y al mismo tiempo conocer la marca, sus inicios, su evolución, la historia de las prendas que tiene en el armario.

La música complementa muy bien la historia, inicia con una melodía instrumental que luego incluye voz, la música se mantiene bastante leve durante todo el film hasta casi el final en que se da paso a cortes de música que muestran distintas escenas y personajes de la supuesta película; para terminar la música aumenta su ritmo y cambia dando un sensación de angustia, a la vez se muestran distintas escenas cortas y el nombre de la marca en un fondo negro.
La música en este film se trabaja de una manera muy similar a los tráileres de películas, en los que al inicio la música se mantiene sutil y conforme va avanzando el tráiler aumenta el ritmo y tonalidad, para explotar al final.

En cuanto a la vestimenta, son las mismas prendas icónicas las que usan los actores en el fashion film, a medida que los sucesos importantes se muestran también se muestran las prendas estrella de cada época; además de otras prendas conocidas de la marca como la bufanda Burberry con estampado a cuadros que utiliza la actriz Sienna Miller en una de las escenas del film.

El producto, en este caso las prendas de Burberry, aparece durante todo el fashion film y desempeña un rol importante dentro de la historia, debido a que toda ella gira en torno al creador de Burberry y como construyó la marca; el producto funciona como un motor y permite el desarrollo de la historia; a pesar de que el film combina momentos personales de la vida de 
Thomas Burberry con los momentos importantes para la evolución de la marca. Sin los productos no existiría nada que contar.

\subsection{Reincarnation by Chanel}

Tabla 3. Ficha de identificación del Fashion film de Chanel

\begin{tabular}{|l|}
\hline Año: Diciembre 2014 para colección 2015 \\
\hline Duración: 7 min 46 seg. \\
\hline Plataforma de difusión: Youtube \\
\hline Link: https://www.youtube.com/watch?v=wO4-TV6Zckc\&t=5s \\
\hline Director: Karl Lagerfeld \\
\hline $\begin{array}{l}\text { Sinópsis: Gabrielle Chanel se va de vacaciones a Austria, en donde encuentra la } \\
\text { inspiración para crear una de sus prendas más icónicas: La Chaqueta Chanel. }\end{array}$ \\
\hline $\begin{array}{l}\text { Personajes: Gabrielle Chanel (Géraldine Chaplin), Princesa Elisabeth "SiSi” de } \\
\text { Austria (Cara Delevingne), Botones y emperador Franz Joseph I (Pharrell Williams) }\end{array}$ \\
\hline Escenarios: Vestíbulo del hotel \\
\hline
\end{tabular}

Fuente: Elaboración propia

\subsubsection{Inventio.}

En este caso, no se ha creado una historia sino que se ha trabajado una representación de la historia detrás del momento en que Gabrielle Chanel se inspiró para crear una de sus prendas icónicas: La chaqueta Chanel. Una forma de dar a conocer al público como se creó esta prenda tan conocida de la marca que en 1954 revolucionó la moda femenina (Inside Chanel, 2017).

En cuanto al gancho, el fashion film logra captar la atención del consumidor desde el inicio, porque presenta una toma cerrada que poco a poco se va ampliando y al mismo tiempo la música va incrementando, una música instrumental con mucha presencia que luego va acompañada de voces agudas. Toda la introducción tiene un toque de misterio que causa curiosidad y anima al espectador a seguir viendo el film.

Por último, la orientación del anuncio es emocional. A través de las imágenes muy cuidadas y agradables estéticamente, se muestran valores como elegancia, poder, belleza, historia. Se presenta no solo la reencarnación de Coco Chanel sino también de Franz Joseph I, quien fue emperador de Austria a fines del siglo XIX y principios del siglo XX y su esposa, Elisabeth de Austria conocida como "Sisi".

\subsubsection{Dispotitio}

En este caso existe una disposición de tres partes: Una introducción muy breve, una parte central que ocupa la mayor parte del film, y un cierre con diálogo. 
- Introducción: Se muestra en interior de un hotel y mientras la cámara retrocede, la toma se va ampliando para mostrar unos cuadros en la pared del emperador de Austria en el siglo XX Franz Joseph I y su esposa, Elisabeth de Austria "Sisi", para luego mostrar el nombre del film: Reincarnation.

- Parte central: Al inicio aparece una mesera, idéntica a la emperatriz mostrada anteriormente, lleva cerveza a uno de los empleados, posa igual que la emperatriz y empuja a otro mesero. Luego se muestra a Coco Chanel, levantándose de su mesa y saliendo del comedor, cuando entra al ascensor se queda mirando la chaqueta que lleva puesta el botones. Finalmente se muestra el vestíbulo en la noche, justo en el momento en que los personajes de las pinturas cobran vida y bailan juntos.

- Cierre unido a diálogo: Se muestra el vestíbulo por la mañana, todos los empleados están haciendo la limpieza y Coco Chanel sale del ascensor para retirarse del hotel, pero antes le hace una pregunta al botones: "Cómo conseguiste esa chaqueta", el botones le responde que fue confeccionada solo para él, a lo que Coco Chanel responde "Entonces, haré una para mí”.

\subsubsection{Elocutio}

En cuanto a la formulación del texto publicitario, en Reincarnation no se hace uso de un eslogan. Además, se utilizan muy pocos diálogos durante el film. Sin embargo, en el cierre si son utilizados y es porque son necesarios para entender el final, así como todo el corto en general.

Coco Chanel muestra interés en la chaqueta del botones desde el primer momento en que la ve, antes de retirarse del hotel le pregunta al botones acerca de la chaqueta y cómo la consiguió. $\mathrm{El}$ botones responde que ha sido confeccionada específicamente para él, y Coco Chanel concluye diciendo "Entonces, haré una para mí".

Es gracias a este diálogo que se entiende de dónde surge la icónica chaqueta Chanel y cómo es que obtuvo la inspiración para crearla, qué es de lo que trata todo el film.

\subsubsection{Memoria}

En este fashion film, solo se muestra explícitamente el nombre de la marca al inicio del film a modo de presentación. Durante toda la historia, no se muestra el nombre ni el logo de la marca. Es hasta el cierre que se hace referencia a Chanel y la chaqueta icónica.

\subsubsection{Actio y Pronuntiatio}

Es muy común que los fashion films sean dirigidos por directores de cine o fotógrafos de moda; en el caso del fashion film Reincarnation; la dirección estuvo a cargo de Karl Lagerfeld, fotógrafo, diseñador y director creativo de la marca Chanel desde 1983. Lagerfeld ha realizado trabajos para marcas como Balmain, Chloé y Fendi.

Las actuaciones estuvieron a cargo Cara Delevingne, modelo y actriz británica que ha tenido papeles en films 
como Anna Karenina y Ciudades de papel; y ha trabajado con marcas como Burberry, H\&M, Dolce and Gabbana, Fendi, etc. y Pharrell Williams cantante, compositor y director estadounidense que además creó el soundtrack del fashion film de Chanel.

Este film fue filmado para acompañar la colección Chanel 2014/2015 y gira en torno al momento en el que Gabrielle Chanel se inspiró para crear la icónica chaqueta Chanel.

El hecho de que el film gire en torno a un momento de la vida de la creadora de la marca Chanel ya es una prueba de que la marca se encontrará reflejada en él. El momento que se muestra es importante para la marca y su camino hacia el éxito, da a conocer la historia detrás de la inspiración que tuvo Coco Chanel para crear la chaqueta Chanel que se volvió muy popular en los 50's.

En el film se observa que Coco Chanel presta atención a la chaqueta del botones del hotel desde el primer momento en que la ve; cuando ya es hora de irse del hotel, Gabrielle Chanel no puede resistirse y le pregunta al botones de dónde ha sacado esa chaqueta, el botones le explica que ha sido confeccionada especialmente para él y ella resuelve "Entonces, haré una para mí". Y en ese momento nace la idea para confeccionar la chaqueta Chanel.

El film recrea las vacaciones de Coco Chanel en Austria, pero además agrega momentos claramente ficticios como cuando los personajes de las pinturas cobran vida y empiezan a bailar y cantar a media noche. Quizás un homenaje al imperio Austriaco; ya que Austria fue el país en donde Chanel encontró la inspiración para la chaqueta y donde además se presentó la colección 2014/2015, inspirada en la época austriaca reflejada en el film.

Figura 6. Protagonistas de Reincarnation

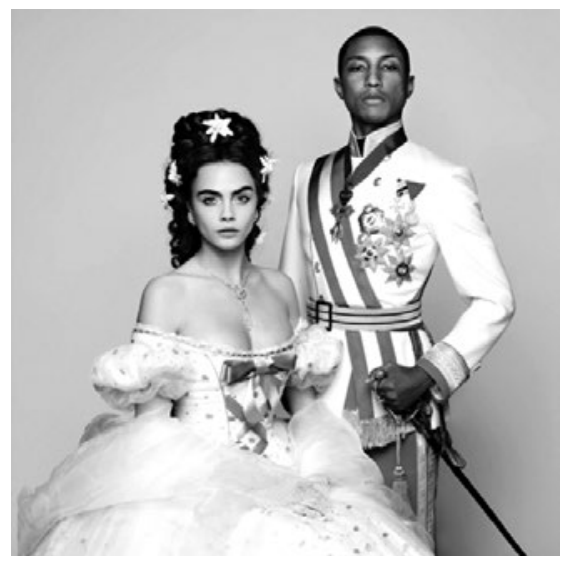

Fuente: Vogue México 
Figuras 7 y 8. Piezas de la colección del desfile Chanel 2014/2015
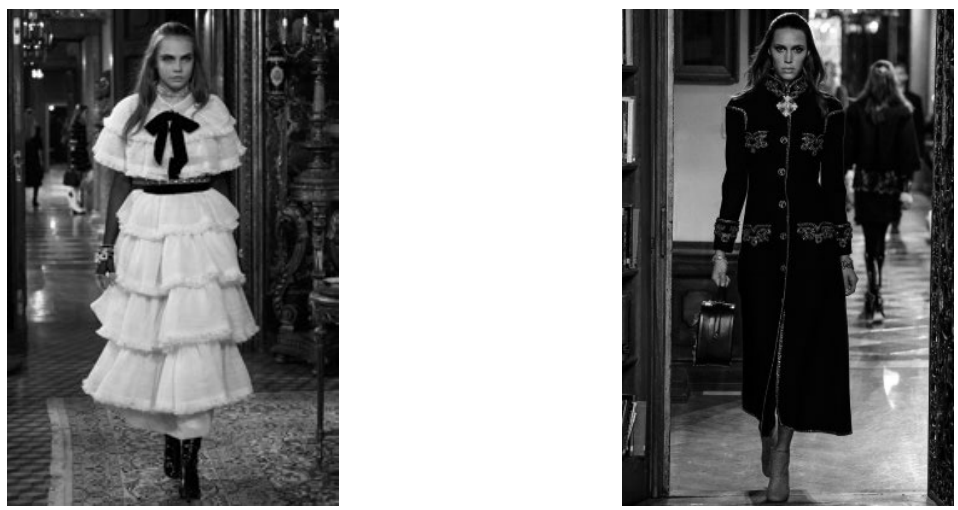

Fuente: Chanel

La mesera es la reencarnación de la emperatriz de Austria Elisabeth "Sisi", a quién se le conocía por su personalidad rebelde; es por ello que la mesera crea desorden y es rebelde dentro de su trabajo al inicio del film; y el botones es la reencarnación del emperador Franz Joseph I de Austria.

Los personajes de emperador y emperatriz de Austria denotan elegancia y clase al bailar, pero además lo hacen al ritmo de una canción cuya letra habla del abrir los ojos y ver el mundo. "Beauty is not hard to define, it is there inside when your open your eyes; hey! Don't be blind, be open to see the world" explica la canción. Esta letra puede tener una similitud con la época en la que Coco Chanel vivía en 1954 en la que la belleza era muy ostentosa y del mismo modo lo era la ropa femenina, con siluetas rígidas y exuberantes, que les impedían a las mujeres moverse con comodidad. La chaqueta
Chanel reinventa la belleza y la moda porque les permite a las mujeres moverse con libertad y no deja de ser una prenda bonita y femenina; es una prenda totalmente diferente a lo que se usaba en ese entonces, Chanel descubre algo nuevo en Austria, y lo trae a su marca.

La música complementa muy bien la historia, al inicio permite crear un sentimiento de misterio, de curiosidad por saber de qué trata el film, por qué muestran esas pinturas, etc. y durante la reencarnación de los emperadores, acompaña perfectamente el baile y el canto de ambos.

La vestimenta y ambientación está acorde a la época y lugar que presenta el film, el personaje de Coco Chanel incluso lleva puesto un conjunto muy parecido al que usaba la verdadera Gabrielle Chanel, con su característico collar de perlas y su boquilla. 
Figura 9. Personaje de Coco Chanel en Reincarnation

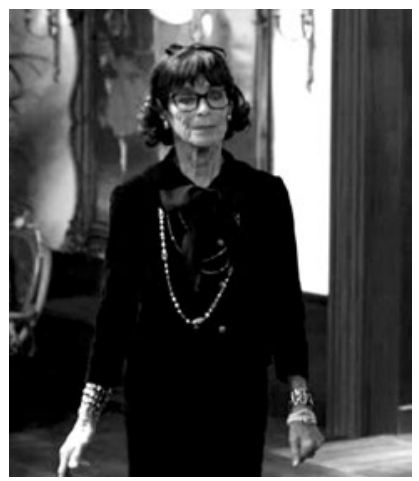

Fuente: Chanel
Figura 10. Coco Chanel

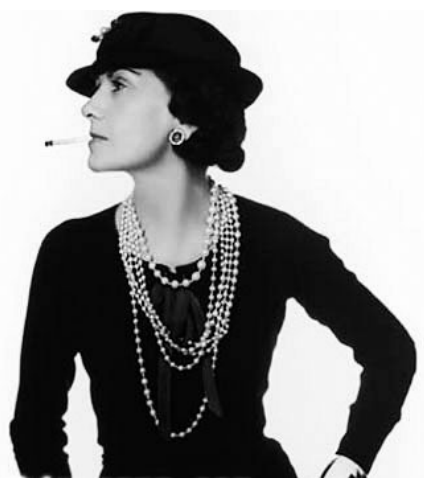

Fuente: The Mancunion
El producto, en este caso la marca Chanel y específicamente la chaqueta Chanel, no aparece explícitamente en el film, el protagonismo se lo llevan los personajes, sin embargo la chaqueta es el motivo por el cual existe el film, porque se cuenta la historia detrás de la creación de la pieza.

\section{Conclusiones}

Las estrategias de publicidad invasiva han dejado de dar resultados satisfactorios, los usuarios han cambiado, se han convertido en prosumidores que no se limitan a observar un anuncio, sino que desean participar e involucrarse con la marca, estos prosumidores buscan marcas capaces de ofrecerle una propuesta de valor; esto ha generado que las marcas se enfoquen en mejorar su contenido y experiencia de usuario, apuntando a una vinculación con el prosumidor.

Hoy en día, gracias al avance de la tecnología y la aparición de las redes sociales, la publicidad tiene un nuevo ca- nal para explotar; las redes sociales juegan un papel importante en la difusión y viralidad de los contenidos de marca. Asimismo obligan a las mismas a crear un contenido de calidad, relevante que realmente llame la atención del prosumidor, debido a este es un entorno en el que el usuario suele prestar atención de manera breve a los contenidos y tiene la libertad y facilidad de pasar a otro contenido que realmente le satisfaga.

En cuanto a la comunicación de moda, las marcas de moda están dirigiendo sus estrategias de comunicación hacia medios digitales y formas de entretenimiento híbridas para conectar con su público. Además se observa una evolución e innovación en la fórmulas comunicativas y en los contenidos, existe una apertura a nuevos perfiles profesionales; si hablamos del caso específico del fashion film, ya no solo se cuenta con un publicista o un comunicador, sino también cineastas, guionistas, actores, etc. lo que supone un enriquecimiento del sector. 
Los fashion films al fusionar arte, cine, música, moda y publicidad permiten no solo abrirse a nuevos perfiles profesionales como ya se mencionó sino incluso a distintos públicos que no solo estén interesados únicamente en moda, sino en cine, arte, fotografía; es así que surgen plataformas como ShowStudio y festivales de fashion films en todo el mundo, en el que se reúnen personas interesadas en moda y personas que disfrutan del placer estético visual que los fashion films otorgan.

En cuanto al análisis de los fashion films: (1) Se puede indicar que las marcas de moda más antiguas, que gozan de una historia larga y rica, suelen contar partes de su trayectoria mediante los fashion films, en el caso de las tres marcas analizadas: Lacoste, Chanel y Burberry, se resalta la historia de la marca o las piezas más antiguas e icónicas de las mismas. (2) También se puede apreciar la tendencia a prescindir de diálogos o utilizarlos de manera mínima, se prefiere contar todo a través de las imágenes acompañadas de música. Se utilizan diálogos cuando es sumamente importante dejar claro algo específico. (3) Asimismo, se intenta pre- sentar la marca o los productos en segundo plano, el protagonista es la historia, a pesar de que en algunos films la historia gire en torno a un producto como en el de Burberry, se procura no saturar al espectador con la muestra de los productos o de la marca.

Para finalizar, los fashion films tienen un gran potencial en la comunicación de moda porque pueden moldearse según los valores de la marca y los transmiten de forma atractiva al prosumidor. Generan una experiencia de marca con alto poder de integración de los valores, la historia, la personalidad de marca. Esto se comprueba con el análisis de los 3 fashion films: Timeless Elegance de Lacoste, The tail of Thomas Burberry de Burberry y Reincarnation de Chanel. Estas tres marcas de moda han utilizado el fashion film para conectar con el prosumidor, y han utilizado como recurso prioritario la narración, el storytelling. En las tres piezas se integran los valores de marca y se logra publicitar el producto de una forma sutil, y al mismo tiempo han logrado ofrecer un contenido diferente, de calidad y que no resulta invasivo.

\section{Bibliografía}

Abaladejo, T. (2005). Retórica, Comunicación e Interdiscursividad. Revista de Investigación Lingüística, 8, 7-33. Recuperado de http://revistas.um.es/ril/article/view/6671

Ahluwalia, P. y Miller, T. (2014). The prosumer. Social Identities. Journal for the Study of Race, Nation and Culture, 20(4-6), 259-261. doi:http://dx.doi.org/10.1080/13504630.2015.1004830 Arbaiza, F. (2017). Marketing experiencial: el marketing a través de las experiencias del consumidor. Piura: Universidad de Piura, Facultad de Comunicación.

Caerols, R. y De la Horra, Y. (2015). Fórmulas creativas en la publicidad de moda. Revista Prisma Social, (14), 336-378. Recuperado de https://dialnet.unirioja.es/servlet/ articulo?codigo $=5435331$ 
Chanel. [Chanel]. (2013, marzo, 13). The jacket - Inside CHANEL [Archivo de video]. Recuperado de https://www.youtube.com/watch?v=zx1R49B_tzw\&t=31s

Chanel. [Chanel]. (2014, diciembre, 1). Reincarnation [Archivo de video]. Recuperado de https://www.youtube.com/watch?v=wO4-TV6Zckc\&t $=7 \mathrm{~s}$

Chanel. [Chanel]. (2014, diciembre, 14). Métiers d'Art 2014/15 Paris-Salzburg Chanel Show [Archivo de video]. Recuperado de https:/www.youtube.com/watch?v=4X86geNxxlA

Costa-Sánchez, C. (2014). El cambio que se viene. Audiovisual branded content. Revista Telos: Cuadernos de comunicación e innovación, (99), 84-93. Recuperado de https://dialnet.unirioja. es/servlet/articulo?codigo $=4955711$

Costa-Sánchez, C. (2014). Transmedia Storytelling, an ally of Corporate Communication: \#Dropped by Heineken case study. Communication and Society, 27(3), 127-150. Recuperado de http://www.unav.es/fcom/communication-society/es/articulo.php?art_id=504

De Assis, J. (2014). Publicidad y Branded Entertainment. Interactividad y otros códigos de entretenimiento. Revista Adcomunica, 7, 87-106. doi: 10.6035/2174-0992.2014.7.6

Del Pino, C. y Castelló, A. (2014). Análisis del Branded Content en televisión: estudio de casos españoles. Revista de Comunicación de la SEECI, 34, 134-149. Recuperado de https:// dialnet.unirioja.es/servlet/articulo?codigo $=4775634$

Del Pino, C. y Castelló, A. (2015). La comunicación publicitaria se pone de moda: branded content y fashion films. Revista Mediterránea de Comunicación, 6(1), 105-128. doi: 10.14198/ MEDCOM2015.6.1.07

Del Pino, C. y Olivares, F. (2006). Brand placement : integración de marcas en la ficción audiovisual. Barcelona, España: Gedisa.

Del Pino, C., Castelló, A. y Ramos-Soler, I. (2013). La comunicación en cambio constante. Branded content, Community Management, Comunicación 2.0 y Estrategia en medios sociales. Madrid, España: Fragua.

Díaz, P. y García, L. (2016). Fashion films as a new communication format to build fashion brands. Communication and Society, 29(2), 45-61. Recuperado de https:/dialnet.unirioja.es/ servlet/articulo?codigo $=5680821$

Gambetti, R. C. y Graffigna, G. (2011). The concept of engagement. A systematic analysis of the ongoing marketing debate. International Journal of Market Research, 52(6), 801-826. doi: 10.2501/S1470785310201661

Gobé, M. (2010). Emotional branding: The new paradigm for connecting brands to people. Nueva York, Estados Unidos: Allworth.

Godin, S., y Bravo, J. A. (2006). ¿̇Todos los comerciales son mentirosos?: Los actuales vendedores de sueños. Barcelona, España: Ediciones Robinbook.

Granitz N. y Forman H. (2015). Building self-brand connections: Exploring brand stories through a transmedia perspective. Journal of Brand Management, 22, 38-59. Recuperado de https://www.scopus.com

Holt, D., Arrese, A. y Pérez-Latre, F.J. (2016). Branding in the age of social media. Harvard Business Review, 40-48. Recuperado de https://hbr.org/2016/03/ branding-in-the-age-of-social-media 
Horrigan, D. (2009). Branded content: a new model for driving Tourism via film and branding strategies. Tourismos: an international multidisciplinary refereed journal of tourism, 4(3), 51-65. Recuperado de http://mpra.ub.uni-muenchen.de/25419/

Jae-Eun, K., Lloyd, S. y Cervello, M. (2016). Narrative-transportation storylines in luxury brand advertising: Motivating consumer engagement. Journal of Business Research, 69(1), 304-313. Recuperado de https://www.scopus.com

Lacoste. [Lacoste]. (2017, mayo, 28). Timeless Elegance, The Film [Archivo de video]. Recuperado de https://www.youtube.com/watch?v=IZC02EQqcXc

Lorán, M. (2017). El uso del cortometraje como estrategia de branded content. Miguel Hernández Communcation Journal, 8, 153-177. Recuperado de https:/dialnet.unirioja.es/ servlet/articulo?codigo $=6120198$

Martin, P. (2015). Fashion films: un vehículo comunicativo de lujo. En J. Benavides (Ed.), El nuevo diálogo social: Organizaciones, públicos y ciudadanos (pp. 775-786). España: Campgrâphic. Recuperado de https://dialnet.unirioja.es/servlet/libro?codigo $=579732$

Mijovic, N. (2013). Narrative form and the rhetoric of Fashion in the promotional Fashion film. Film, Fashion छ Consumption, 2 (2), 175-186. doi: https://doi.org/10.1386/ffc.2.2.175_1

Sáez, S., \& Alvarado, M. (2015). El Fashion film como emblema de las marcas de alta costura: delimitación conceptual, características y funciones comunicacionales (tesis de grado). Universidad de Valladolid, España. Recuperado de http://uvadoc.uva.es/handle/10324/15804

Spang, K. (2005). Publicidad y retórica. En M. Romero (Coord.). Lenguaje Publicitario (pp.2742). Barcelona, España: Ariel.

Torres, E. (2013). Estrategias publicitarias eficaces ante el nuevo consumidor. En J. Benavides (Ed.), El nuevo diálogo social: Organizaciones, públicos y ciudadanos (pp. 675-694). España: Campgrâphic. Recuperado de https://dialnet.unirioja.es/servlet/libro?codigo $=579732$

Tur-Viñes, V. y Segarra, J. (2014). Branded content y storytelling. El arte de crear contenidos y contar historias. En R. Ron, A. Alvarez y P. Nuñez (Coord.), Bajo la influencia del branded content: efectos de los contenidos de marca en niños y jóvenes (pp.117-136). Madrid, España: Esic.

Uhrilova, M. (2013). 100 Years of the Fashion Film: Frameworks and Histories. Fashion Theory Journal, 17 (2), 137-158. doi: 10.2752 / 175174113 X13541091797562

Vogue. (2014, noviembre, 24). Cara, Pharrel Williams y Chanel. Recuperado de http://www. vogue. $\mathrm{mx} / \mathrm{moda} /$ estilo-vogue/articulos/filme-reincarnation-de-chanel-con-cara-delevingne -y-pharrell-williams/4543

Wang, J. y Juhlin, O. (2017). Fashion, Fiction, Function: Mediating wearable design through fashion film. Nordic Design Research, 7. Recuperado de http://www.nordes.org/nordes2017/ assets/full_papers/nordes17a-sub1068-cam-i26_WANG_v2.pdf

Wilson, H. (2012, diciembre, 6). 1920s Fashion Icon: Coco Chanel. Recuperado de http://mancunion.com/2012/12/06/1920s-fashion-icon-coco-chanel/ 